\title{
Transparência e gestão do conhecimento por meio de um banco de teses e dissertações: a experiência do PPGEP/UFSC
}

Roberto Carlos dos Santos Pacheco

Doutor em Engenharia de Produção. Coordenador do Grupo STELA desenvolvedor do sistema de Banco de Teses e Dissertações do PPGEP/ UFSC

E-mail: pacheco@eps.ufsc.br

Vinícius Medina Kern

Doutor em Engenharia de Produção. Coordenador do Núcleo de Mídia Científica do PPGEP/UFSC e professor da UNIVALI São José E-mail: kern@eps.ufsc.br

\section{Resumo}

Em 1995, o Programa de Pós-Graduação em Engenharia de Produção da Universidade Federal de Santa Catarina (PPGEP) UFSC) digitalizou e disponibilizou, de forma institucional, teses e dissertações defendidas no programa. Inicialmente um repositório de documentos digitais, o BTD (Banco de Teses e Dissertações) do PPGEP transformou-se em sistema único de conjugação de recursos bibliométricos e informétricos, tendo como base as teses e dissertações do programa e a medição de acessos. Além dos produtores de conhecimento (alunos e professores), o BTD atende a tomadores de decisão e a gestores do sistema de pósgraduação, subsidiando-os com informações sobre nível de interesse e intercâmbio de conhecimento entre cada uma das áreas de concentração do programa. O presente artigo apresenta a origem, principais características, fundamentos teóricos, funcionais e as perspectivas de desenvolvimento do projeto BTD.

\section{Palavras-chave}

Bibliotecas digitais; Arquivos abertos; Informetria; Bibliometria; Bancos de teses; Intercâmbio e compartilhamento de informações; Gestão do conhecimento.

Transparency and knowledge management in a theses and dissertations database: the PPGEP/UFSC experience

\begin{abstract}
In 1995, the Graduate Program in Production Engineering of the Federal University of Santa Catarina (PPGEP/UFSC) digitalized and made available its theses and dissertations. From a digital document repository, the Theses and Dissertations Database (BTD) was changed into a system that combines bibliometry and informetry features. Statistics are maintained about all accesses to BTD. Besides knowledge producers (students and professors), BTD helps the decision makers and managers of the graduate system. They use it to measure interest and knowledge interchange among PPGEP research areas. This article presents the origin, main features, theoretical and functional bases of BTD, and perspectives for further development.
\end{abstract}

\section{Keywords}

Digital libraries; Open archives; Informetry; Bibliometry; Electronic theses/dissertations; Information interchange and sharing;

Knowledge management.

\section{INTRODUÇÃO}

O incremento da organização cooperativa e a agregação de esforços têm sido apontados como direções para o desenvolvimento de bibliotecas virtuais ${ }^{1}$. Este desenvolvimento pode ser atingido mediante a interoperabilidade entre vários aplicativos ou por colaboração sobre uma ferramenta aberta única.

Uma das questões-chave para a construção de ambientes colaborativos está na consideração dos diversos atores que contribuem ou utilizam os recursos da biblioteca digital. Projetos de concepção centrados exclusivamente nos escritores e leitores atendem apenas a uma parcela dos atores efetivamente envolvidos com educação, ciência e tecnologia. Dentre os excluídos, destacam-se os gestores do processo de geração do conhecimento, para quem são mais úteis os indicadores informétricos do que o detalhamento bibliométrico.

Especificamente no cenário de produção de teses e dissertações, além de pós-graduandos, professores e pesquisadores, a biblioteca digital deve atender aos gestores do processo de construção do conhecimento. São os coordenadores de área, gestores de turmas, líderes de grupos de pesquisa e a coordenação do programa de pósgraduação. Além do conteúdo das teses e dissertações, informações sobre freqüência de acessos por tema, palavrachave, orientador, teses, dissertações, área de concentração e ano de publicação podem ser subsídios valiosos aos seus respectivos processos de tomada de decisão.

O Banco de Teses e Dissertações (BTD) do Programa de Pós-Graduação em Engenharia de Produção da Universidade Federal de Santa Catarina (PPGEP/UFSC) foi criado com essa concepção. Desde seu surgimento, em 1995, o BTD contempla até o presente momento 664 trabalhos em texto completo entre os 2.137 trabalhos de conclusão de mestrado e doutorado já defendidos no programa desde 1970 até novembro de 2001. Além disso, o BTD acresce o acesso ao conteúdo dos trabalhos uma série de estatísticas de busca. Estas estatísticas têm embasado a tomada de decisão de gestores do PPGEP/ UFSC. 
Transparência e gestão do conhecimento por meio de um banco de teses e dissertações: a experiência do PPGEP/UFSC

O presente artigo objetiva apresentar a experiência de concepção, construção e operação do BTD do PPGEP/ UFSC. Inicialmente, discute-se a importância de bancos digitais para o processo público de construção de conhecimento e transparência de informações. Na seqüência, apresentam-se histórico, formação e constituição atual do BTD, com destaque para suas funcionalidades em termos de informetria. Ao final, o artigo apresenta os desenvolvimentos em andamento e as perspectivas do BTD.

\section{BIBLIOTECAS DIGITAIS E UNIVERSIDADE PÚBLICA}

Recentemente, Lawrence ${ }^{2}$ demonstrou que artigos disponíveis on-line são mais citados do que os nãodisponíveis. A disponibilidade de trabalhos acadêmicos em bibliotecas digitais beneficia os pesquisadores acadêmicos. Este benefício, no entanto, depende do nível de disponibilidade e facilidade de acesso oferecidos. Bibliotecas digitais bem aparelhadas e ricas em conteúdo só atingirão seu pleno potencial, se oferecerem acesso a custo baixo.

Um mestre ou doutor em formação tem nas bibliotecas digitais um recurso inestimável. Enquanto nas bibliotecas tradicionais o pesquisador se defronta com limitações de tempo, espaço e outros recursos, as bibliotecas digitais lhe oferecem ubiqüidade, baixo custo e facilidades de pesquisa. Assim, a produtividade de um pesquisador em formação tende a aumentar.

A formação de recursos humanos e a produção científica brasileira dependem em grande parte do investimento de recursos públicos. Formar mestres e doutores mais produtivos equivale a investir melhor os recursos públicos. $O$ resultado deste investimento dificilmente pode ser medido com precisão - a riqueza gerada está principalmente na mente dos pesquisadores formados. Por outro lado, os trabalhos defendidos pelos pós-graduados são resultados concretos do investimento de recursos públicos na formação de pós-graduação que podem (ou devem) estar à disposição da sociedade.

Baggio $^{3}$ observa que se o conhecimento acumulado não é compartilhado com a sociedade, agrava-se o abismo que separa ricos e pobres. Ao disponibilizar sua produção por meio de bibliotecas digitais bem aparelhadas, a pósgraduação brasileira tem a oportunidade de expor a qualidade do que produz para o grande público e, assim, promover sua integração com o restante da sociedade, até mesmo para captar mais recursos. Neste sentido, parece saudável e necessário oferecer (ou devolver) ao público o resultado do investimento de recursos públicos na pósgraduação. A próxima seção descreve uma iniciativa do PPGEP/UFSC que tem esta orientação.

\section{HISTÓRIA DO BANCO DE TESES E DISSERTAÇÕES DO PPGEP/UFSC}

\section{Origem}

Em 1985, o planejamento estratégico do PPGEP/UFSC estabeleceu como meta de dez anos a constituição de um programa de ensino a distância que permitisse ao aluno de pós-graduação o acesso ao conteúdo, livre de restrições geográficas, com base na utilização da tecnologia da informação e telecomunicações. Em julho de 1995, o Laboratório de Ensino a Distância (LED) instalou sua infra-estrutura de videoconferência, para, mais tarde, começar o mestrado junto a outras universidades do estado*.

As atividades do LED têm sido inspiradoras para universidades e centros de educação a distância do país ${ }^{4}$. Além da tecnologia necessária às aulas e atividades de orientação, o programa já reconhecia a necessidade de constituir bibliotecas digitais próprias para seus alunos a distância, bem como de agregar suas estruturas administrativas e acadêmicas sob uma mesma plataforma tecnológica. O Banco de Teses e Dissertações do programa nasce, em 1995, com a finalidade de disponibilizar a memória das teses e dissertações do PPGEP a todos seus alunos, orientadores, pesquisadores, gestores e à sociedade, destacando a transparência no processo de produção de conhecimento do programa.

O BTD foi constituído cerca de um ano após o surgimento dos navegadores Netscape ${ }^{\circledR}$ e Mosaic ${ }^{\circledR}$. No Brasil, a infraestrutura de internet dedicava ao link catarinense $64 \mathrm{Kbps}$ de conexão. O desconhecimento do meio internet e a precariedade da infra-estrutura foram os primeiros desafios na constituição do BTD. Na infra-estrutura, uma vez mais o programa de ensino a distância do PPGEP/UFSC catalisou o desenvolvimento mediante um acordo com o governo do estado de Santa Catarina, que elevou a velocidade de tráfego para $2 \mathrm{Mbps}$.

Para a digitalização das dissertações foram usados os arquivos entregues pelos alunos para obtenção do título de mestre ou doutor. Constituiu-se uma equipe de digitalizadores, que transformavam os arquivos em formato binário .DOC (próprio de editores de texto como

\footnotetext{
* Com o apoio da Fundação de Ciência e Tecnologia (Funcitec) de Santa Catarina e da Coordenação de Aperfeiçoamento de Pessoal de Nível Superior (Capes).
} 
Word ${ }^{\circledR}$ e StarOffice $\left.{ }^{\circledR}\right)$ para formato de texto com marcação HTML. A primeira dissertação do PPGEP foi colocada no site do programa no início de 1996. Entre 1996 e 1999, foram manualmente transformadas e disponibilizadas no BTD 357 teses e dissertações. Nesse período, lançaram-se projetos como o do Massachussets Institute of Technology ${ }^{5}$, ProQuest-UMI ${ }^{6}$, Virginia Tech ${ }^{7}$ e TB-IBICT ${ }^{8}$, entre outros.

\section{BTD DA ENGENHARIA QUÍMICA}

Em 1999, um projeto do Grupo Stela* do PPGEP/UFSC desenvolveu o primeiro banco digital de teses em engenharia química, com informações de todos os programas da área no país, como ilustra a figura 1. O banco digital ${ }^{9}$ é hospedado pelo Curso de PósGraduação em Engenharia Química da Universidade Federal de Santa Catarina (CPGEnq/UFSC).

Para constituição do BTD nacional em engenharia química, incluíram-se, na logística de captura e tratamento dos metadados das teses e dissertações, as informações eletrônicas disponíveis em todos os programas de pósgraduação, geradas para subsidiar a avaliação da Coordenação e Aperfeiçoamento de Pessoal de Nível Superior (Capes). Para cada programa do país em engenharia química, o mesmo arquivo gerado para a Capes é importado para a base de teses e dissertações, o que permitiu a inclusão de um legado nacional de três anos, de forma automática. Os textos completos podem ser incluídos por meio do Sistema Administrador, que também gerencia a segurança e autorização de acesso de cada um dos coordenadores de engenharia química. O projeto BTD da Engenharia Química serviu de base para a conformação do atual BTD do PPGEP.

\section{BTD - VERSÃO 2001}

Em 2000, o Grupo Stela reuniu o conjunto de arquivos digitalizados no BTD, unindo-os à Plataforma de Gestão Acadêmica do PPGEP/UFSC por meio do enlace entre os arquivos e os correspondentes registros administrativos das teses e dissertações defendidas no programa. Enquanto os arquivos físicos eram ligados aos seus correspondentes metadados, procedeu-se a definição do site do BTD, com a especificação dos serviços e recursos disponíveis aos diferentes usuários (figura 2).

\footnotetext{
* Grupo formado por professores, alunos de mestrado e doutorado do PPGEP/UFSC e de outros cursos da UFSC, Univali e Unisul, com base na concepção e construção de sistemas de informações e aplicação de técnicas de inteligência artificial. O Grupo Stela é, também, o desenvolvedor co-responsável pela Plataforma Lattes do CNPq.
}

FIGURA 1

Banco de Teses e Dissertações da Engenharia Química Brasileira $^{9}$
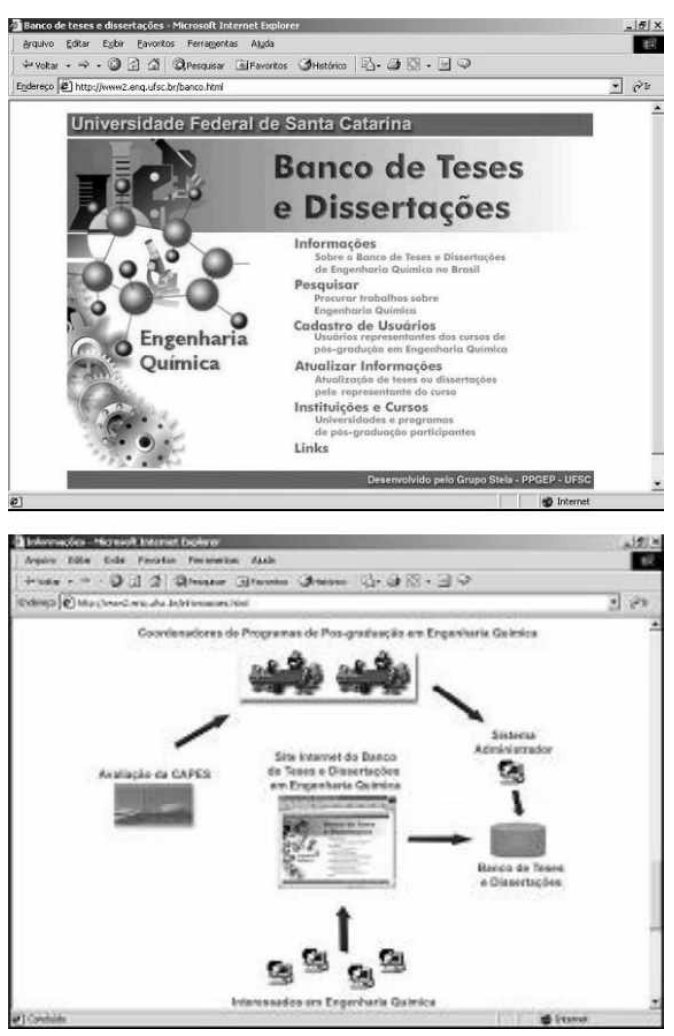

FIGURA 2

Banco de Teses e Dissertações do PPGEP ${ }^{10}$

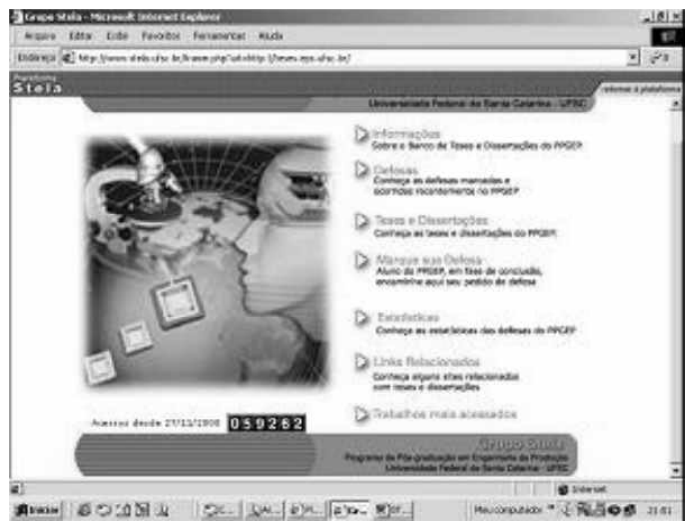

Serviços do Site do BTD

Informações: informações sobre o BTD (objetivos, origem e principais características). Defesas: permite verificar as defesas marcadas para os próximos dias e as que ocorreram nos últimos quatro meses do programa.

Teses e Dissertações: permite acessar o acervo de teses e dissertações do PPGEP, com buscas filtráveis por orientador, examinador, área, ano, nível do curso.

Marque sua Defesa: para alunos concluintes enviarem sua solicitação defesa aos orientadores e secretaria.

Estatísticas: indicadores diversos (tempo de titulação por ano, defesas por área, estatísticas por docente do PPGEP etc.)

Links Relacionados: links para sites relacionados e notícias sobre o BTD.

Trabalhos mais acessados: estatísticas de acesso por trabalho, tema ou orientador. 
Transparência e gestão do conhecimento por meio de um banco de teses e dissertações: a experiência do PPGEP/UFSC

O site foi lançado em dezembro de 2000. Com menos de um ano de existência, atingiu a marca dos 59 mil acessos (em maio de 2001, completaram-se 23 mil acessos). Alunos, docentes e interessados nas atividades de pesquisa do PPGEP/UFSC encontram no BTD fontes de pesquisas nas diferentes áreas do programa. Nas próximas seções, apresentam-se as principais características e recursos atualmente disponíveis no BTD.

\section{FUNCIONALIDADES E INOVAÇÕES NO BTD}

O site do BTD do PPGEP/UFSC está divido em sete áreas de recursos oferecidos aos usuários: informações gerais, defesas marcadas ou recentemente realizadas, acesso aos documentos e informações sobre trabalhos defendidos (teses, dissertações e exames de qualificação de doutorado) no PPGEP/UFSC, serviço de marcação de defesas por parte de alunos concluintes, estatísticas sobre os trabalhos de conclusão de curso no PPGEP/UFSC, links relacionados aos assuntos do BTD e indicadores de acesso segundo diversos critérios de consultas.

\section{Defesas (marcadas e recentes)}

Esse link tem por objetivo divulgar as próximas defesas marcadas no programa, permitindo aos interessados escolher defesas a que gostariam de assistir, ou contatar os mestres ou doutores que recém-concluíram seu curso no programa e estão em fase final de preparação da tese ou dissertação. Os interessados podem conhecer as próximas defesas ou aquelas ocorridas nos últimos quatro meses, segundo área de concentração, nível do curso, ou data.

\section{Teses e dissertações}

Trata-se do link mais acessado do BTD, pois é o que permite acesso aos 664 documentos completos disponibilizados no site. Para conhecer uma tese ou dissertação do PPGEP/ UFSC na íntegra, o usuário tem quatro estágios de consultas: (a) termos e configuração da busca; (b) resultado da consulta; (c) detalhamento da tese ou dissertação desejada; (d) leitura do documento (quando disponível). A figura 3 apresenta esses estágios, desde a consulta por termos até a apresentação integral do documento desejado.

Para as consultas, o usuário pode incluir termos livres para buscas nos títulos, resumo, autor ou palavras-chave dos trabalhos. Além da busca por termos, o usuário pode filtrar suas consultas com o acréscimo de classificadores que permitem encontrar as teses e dissertações: a) de um determinado orientador do programa; b) de um determinado examinador do PPGEP/UFSC (isto é, todas bancas de que participou); c) de um determinado
FIGURA 3

Estágios no Acesso às Teses e Dissertações do BTD: (a) consulta; (b) resultados; (c) detalhamento; (d) documento completo.
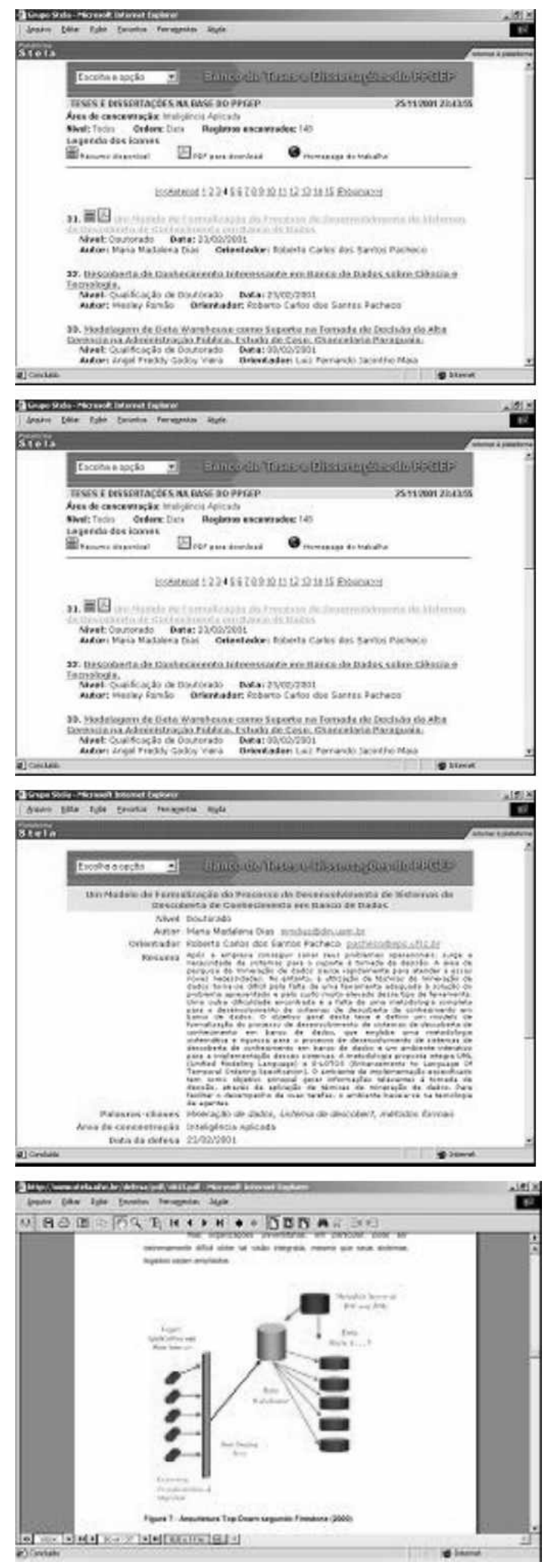
examinador externo; d) de um determinado tutor de orientação (doutorando que co-orienta trabalho de mestrado); e) de uma determinada área de concentração; f) de um dos três níveis de trabalhos disponíveis (mestrado, qualificação ou doutorado); g) de um determinado ano da defesa.

A combinação de parâmetros pode resultar em buscas temáticas de interesses diversos à pós-graduação. A busca por "centrais de frete", por exemplo, aponta seis dissertações no PPGEP defendidas entre 1998 e 1993. A apresentação desta busca específica permitiu ao programa apresentar, em tempo real, seu know-how institucional sobre o referido tema em uma das visitas do presidente de uma empresa de telecomunicações interessado em trabalhos universitários ligados ao atendimento de centrais de frete. Exemplos como este têm evidenciado o papel institucional e destacado o caráter de ferramenta de gestão de conhecimento do BTD.

\section{Estatísticas}

O link "Estatísticas" (figura 4) do BTD foi concebido para atender aos gestores do programa e aos interessados em conhecer diversos indicadores referentes às teses $\mathrm{e}$ dissertações defendidas no PPGEP/UFSC. Seu acionamento gera cálculos diretos e on-line sobre o sistema acadêmico do PPGEP/UFSC. As estatísticas incluem tempo de titulação por ano e a distribuição de defesas por área de concentração. Podem ser gerais, para todo o programa, ou específicas a um orientador.

Uma das principais contribuições do BTD à administração da pós-graduação é a apresentação de estatísticas. A constatação da redução do tempo médio de titulação no programa e, em especial, o comparativo nos tempos de titulação nas três modalidades de mestrado do PPGEP/ UFSC (presencial, fora de sede e presencial virtual) dão conhecimento da natureza e resultados das atividades de orientação nessas três modalidades. Em virtude dos indicadores que proporciona, o BTD tem-se constituído, também, em instrumento para análise da atividade de orientação.

O menor tempo de titulação para os mestrados por videoconferência (modalidade presencial virtual) já é objeto de estudo do programa, que atribui, ao seu sistema avançado de orientação, uma das principais razões para esse fato, além da identidade dos mestrandos da modalidade com suas instituições de origem, normalmente alvo de estudo de suas dissertações, já no período de créditos.

\section{FIGURA 4}

\section{Estatísticas do BTD}

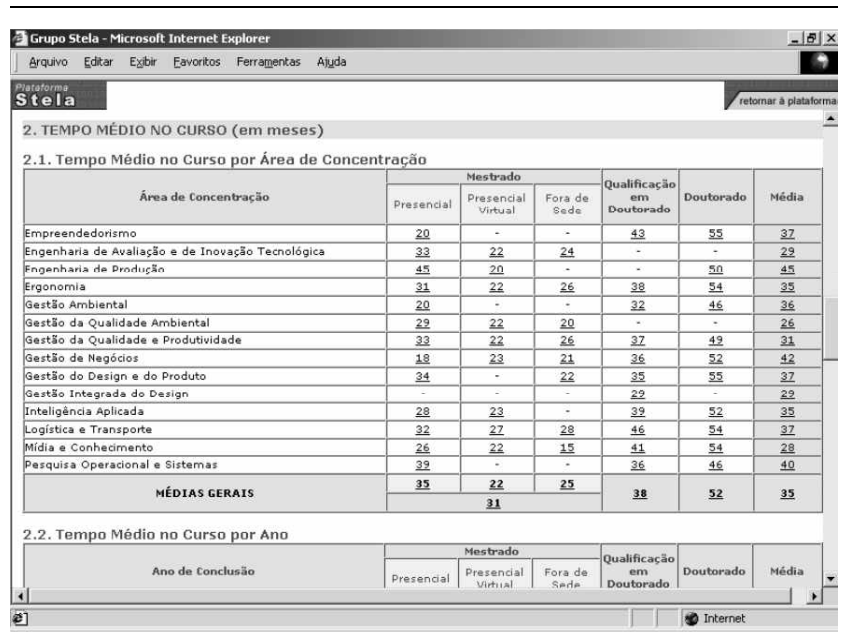

Estatísticas

Link com indicadores estatísticos com base nos trabalhos de conclusão do Programa. Os indicadores permitem conhecer a evolução anual do tempo de titulação, a distribuição por área de concentração e os indicadores individuais por orientador.

\section{Trabalhos mais acessados}

Um dos recursos inéditos no BTD está no controle detalhado dos acessos às teses e dissertações do programa. Foi criado para acompanhar o nível de interesse dos usuários do BTD em cada um dos trabalhos de conclusão disponibilizados.

As estatísticas de acesso permitem a classificação por dissertação ou tese, por orientador ou por área de concentração mais acessados. A figura 5, a seguir, apresenta as três possibilidades de classificações dos acessos às teses e dissertações do PPGEP/UFSC.

A primeira possibilidade apresenta os 100 trabalhos mais acessados segundo o número total de consultas. A segunda classificação dos acessos traz a média ponderada de acessos para os orientadores no PPGEP/UFSC, na qual são considerados todos os acessos dos trabalhos orientados e o total de trabalhos orientados por professor individualmente. O resultado é uma lista com os nomes dos orientadores e os índices de acesso. Ao clicar sobre o nome de um orientador, o usuário abre página específica sobre o docente do programa, com todos os trabalhos orientados, link para suas estatísticas individuais e para o seu Currículo Lattes, disponível na página da Plataforma Lattes do CNPq. A terceira classificação apresenta o total de acessos segundo cada área de concentração do PPGEP/UFSC. 
Transparência e gestão do conhecimento por meio de um banco de teses e dissertações: a experiência do PPGEP/UFSC

O controle dos acessos e suas diferentes formas de classificação são uma das características de maior destaque do BTD. O programa de pós-graduação apresenta, nesses indicadores, elementos comparativos do nível de atividade e de interesse em cada uma de suas áreas temáticas e de cada um de seus orientadores. Seus resultados têm subsidiado decisões do colegiado do PPGEP/UFSC, como o recente estudo para a divisão do programa em três eixos temáticos. Outra característica conseqüente da transparência dos indicadores de acesso é o incentivo de orientadores a orientandos para a disponibilização de trabalhos, visando a aumentar a visibilidade da produção de ambos.

\section{PERSPECTIVA PRESENTE E FUTURO}

A disponibilidade do BTD, com as funcionalidades descritas neste artigo, já representa significativo avanço na forma de pesquisar e produzir conhecimento no âmbito da pós-graduação. Os números de acessos sugerem o vigor com que a introdução de novas tecnologias afetou o modo de trabalho dos pós-graduandos. Por outro lado, a disponibilidade de indicadores de interesse dos gestores da pós-graduação dotou o sistema de recursos valiosos para apoiar a tomada de decisão.

Novos desenvolvimentos estão previstos para o BTD, especialmente nas áreas de jornalismo científico e gestão do conhecimento. O primeiro aspecto deverá ser abordado através de entrevistas com formandos, orientadores e examinadores em bancas de defesa de teses e dissertações. Planeja-se apresentar, em linguagem acessível a não envolvidos diretamente com o trabalho, seu significado e a contribuição oferecida à ciência e à sociedade como um todo.

Novas funcionalidades devem ser adicionadas às já existentes no BTD. No que concerne à gestão do conhecimento, pretende-se aprimorar as ferramentas de busca, de forma a permitir buscas mais amplas em texto completo e, assim, favorecer a construção de indicadores informétricos além do que é possível no presente. Também, objetiva-se agregar ferramentas para a verificação de consistência metodológica, bem como a gestão do conhecimento organizacional da pós-graduação por meio do perfil de orientação de seus docentes, áreas e temas mais freqüentes nos trabalhos de conclusão. Ainda, pretende abranger o acompanhamento de egressos por intermédio de um banco de talentos e da conseqüente interação com as organizações às quais estão associados os egressos.
FIGURA 5

Link "Trabalhos mais acessados": a) ranking por autores; b) ranking por orientador; c) acesso à página de teses $\mathrm{e}$ dissertações orientadas pelo orientador selecionado; c) ranking por área de concentração.

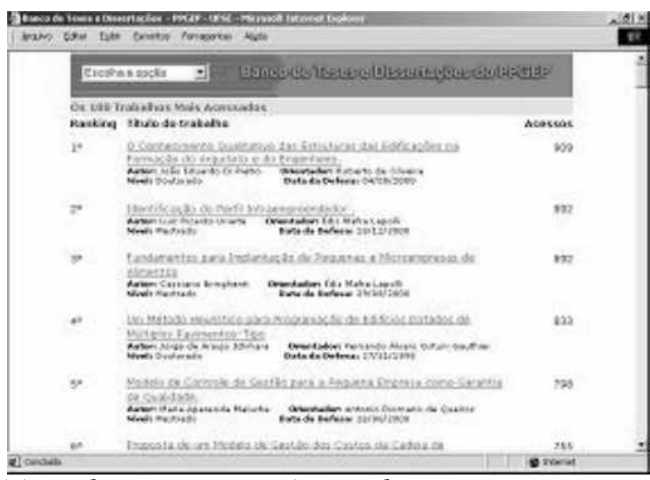

(a) Ranking por autores (teses e dissertações mais acessadas)

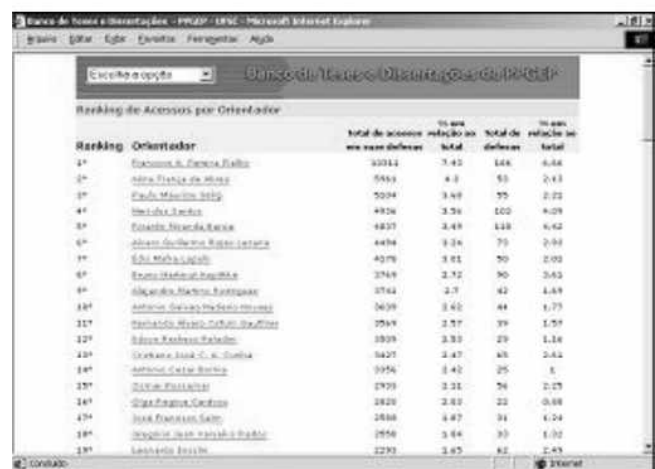

(b) Ranking por orientadores

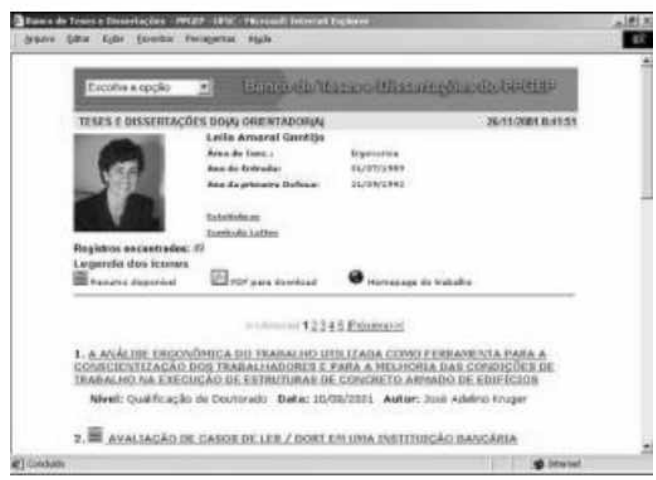

(c) Página do orientador (teses/dissertações orientadas)

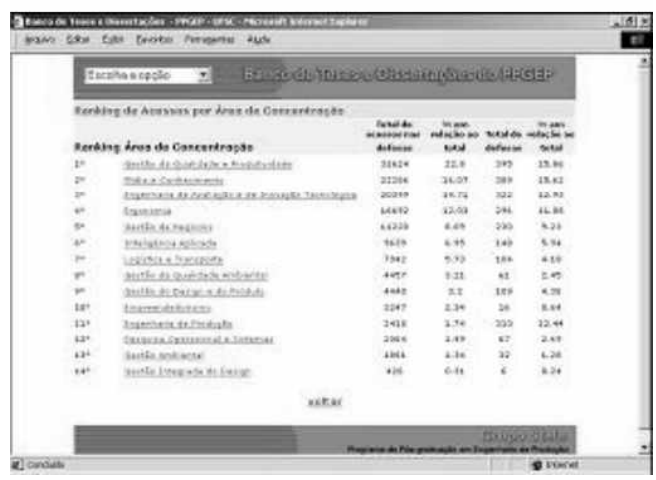

(d) Ranking por área de concentração do programa 
Outro tema de estudo no PPGEP/UFSC é a aplicação de métodos de auditoria combinados com ferramentas de inteligência artificial na análise de metodologia científica. Entre os resultados desta aplicação, está a possibilidade de detecção de plágio. Técnicas de análise de texto são combinadas com diferentes metadados metodológicos com o objetivo de auxiliar os candidatos a verificar a adequação do texto à metodologia científica correspondente ao nível do seu trabalho.

Além disso, o BTD deverá subsidiar a aplicação de sistemas inteligentes auditores. Estes sistemas têm por objetivo comparar conteúdos e classificar citações ou recompilações. Tanto a verificação metodológica automática quanto a aplicação de sistemas inteligentes auditores são temas de dissertações do PPGEP/UFSC.

Este conjunto de funcionalidades, uma vez implementado, tende a acelerar um processo de mudança no ambiente universitário que aparentemente se inicia. O futuro da universidade é aventado a seguir, especificamente quanto à biblioteca universitária e ao papel do bibliotecário de referência.

\section{O FUTURO DO BIBLIOTECÁRIO DE REFERENCIA}

Cunha $^{11}$, em seu estudo sobre o futuro da biblioteca universitária brasileira, prevê que "as tecnologias de informação afetarão tanto as atividades acadêmicas quanto a natureza do empreendimento em educação superior", com reflexos na biblioteca universitária. Chama a atenção para o fato de que a simples introdução de novas mídias para o transporte da informação não mudará a natureza da educação superior, mas sim a habilidade com que forem introduzidas as novas abordagens ao aprendizado.

Esta introdução de novas tecnologias tem suscitado debates. Discute-se o futuro, ou mesmo o fim da função do bibliotecário de referência ${ }^{11,12}$. Vergueiro ${ }^{13}$ resenha Crawford \& Gorman ${ }^{14}$, que vêem uma "tendência suicida" nos bibliotecários que defendem a desintermediação - a idéia de que cada usuário pode ser seu próprio bibliotecário de referência. Segundo estes, comparando o trabalho do bibliotecário de referência ao de outros técnicos, "mesmo aceitando que a maioria dos adultos poderia aprender a consertar seus próprios carros, encanamento, e trabalho elétrico - uma suposição que leva a um mundo até mesmo mais perigoso do que o de hoje - por que diabos o fariam?" 14
A comparação não nos parece apropriada. Uma comparação adequada seria: "Se um adulto pode acender a luz pressionando um interruptor, por que chamaria um eletricista?". O mesmo vale para dirigir (e não consertar) um carro, ou para obter água (e não construir um sistema de encanamento). Cunha ${ }^{11}$ observa que há grande número de usuários que necessita aprender como navegar na Internet, enquanto pequeno grupo de usuários deseja ir diretamente às fontes. Estes últimos, seguindo a mesma analogia, ainda precisam trabalhar como eletricistas, mecânicos e encanadores, mas não por muito tempo.

O bibliotecário de referência continuará sendo o especialista, mas o modo como trabalha certamente será alterado pelas novas tecnologias. Arellano ${ }^{15}$ lista serviços de referências na Web nos quais é possível obter o apoio de bibliotecários profissionais. Considerando que alguns destes serviços funcionam sem interrupção, existe uma tendência de automatização para racionalizar recursos.

Os serviços do bibliotecário (ou de qualquer outro tipo de profissional) dificilmente serão substituídos completamente por computadores, mas também não parece provável que o avanço da automatização seja impedido para manter proprietários ou zeladores da informação, a quem os interessados devem solicitar a permissão de acesso. Muito pelo contrário: Mason et alii ${ }^{1}$ observam que os bibliotecários estão, sim, encontrando o tempo necessário para ganhar proficiência no uso das tecnologias, pois vêem nisso um esforço importante para benefício de seus usuários.

\section{O FUTURO DAS BIBLIOTECAS DIGITAIS}

O avanço das novas tecnologias na área de bibliotecas é evidente. No entanto, a realização é muito pequena, se comparada ao potencial realizável. Cada universidade ou cada programa de pós-graduação desenvolve, ainda, iniciativas pouco integradas. Provedores de informação privados oferecem soluções também pouco integráveis ao restante do ambiente bibliotecário.

A possibilidade de integração de bibliotecas digitais depende da construção de padrões que permitam o intercâmbio de informações e a interoperabilidade de aplicativos. A busca por interoperabilidade entre arquivos abertos, segundo Sena ${ }^{16}$, "visa a transformar cada um dos arquivos em parte de um arquivo global para a realização de pesquisas on-line". Caplan ${ }^{17}$ observa que o desenvolvimento de padrões na área de bibliotecas digitais é difícil, porque não há, ainda, a formação de uma comunidade que assuma a liderança na construção de um vocabulário comum e estruturas de colaboração. 
Transparência e gestão do conhecimento por meio de um banco de teses e dissertações: a experiência do PPGEP/UFSC

Neste sentido, o Brasil pode oferecer o exemplo da ontologia LMPL (Linguagem de Marcação da Plataforma Lattes $^{18}$ ) para informações sobre currículos, que consiste de um vocabulário e gramática definidos pelo consenso de nove universidades, prestando-se à integração de aplicativos e bases de dados nesta área. Uma iniciativa semelhante na área de bibliotecas digitais pode colocarnos na vanguarda do desenvolvimento de bibliotecas digitais universitárias.

Uma iniciativa recente, liderada pelo Instituto Brasileiro de Informação em Ciência e Tecnologia (IBICT), é a formação do Consórcio Brasileiro de Teses e Dissertações, com a participação da USP (Projeto Cidade do Conhecimento), PUC-RJ (Teses e Dissertações Digitais), PPGEP/UFSC (BTD), Bireme e CNPq. O consórcio, formado em setembro de 2001, trabalha em uma definição nacional de metadados para teses e dissertações segundo o padrão internacional Dublin Core ${ }^{19}$.

A constituição de um padrão para metadados deverá instrumentalizar mecanismos de busca do tipo colheita (harvesting) sobre teses e dissertações brasileiras. O Banco Digital de Teses e Dissertações em estudo pelo consórcio deverá ser o projeto inaugural da Biblioteca Digital Brasileira $^{20}$ (BDB) do IBICT.

\section{CONSIDERAÇÕES FINAIS}

Este artigo apresentou a experiência do PPGEP/UFSC na construção de seu Banco de Teses e Dissertações, enfatizando a transparência da informação e a gestão do conhecimento. O papel das bibliotecas digitais na universidade pública foi discutido. A história da construção do BTD foi contada, juntamente com o detalhamento de suas funcionalidades e inovações. Foram aventadas perspectivas de desenvolvimento atuais e futuros do BTD, o futuro das bibliotecas digitais e dos bibliotecários de referência.

A tecnologia e a metodologia de construção do BTD do PPGEP/UFSC têm feito parte do esforço continuado de construção da Plataforma Lattes de informações em ciência e tecnologia no país. A Plataforma Lattes foi concebida e operada sob a óptica do fomento, planejamento e avaliação em ciência e tecnologia. IBICT, CNPq e Bireme têm investido esforços para a integração desta plataforma, com a disponibilização de documentos eletrônicos prevista para a BDB.

Ci. Inf., Brasília, v. 30, n. 3, p. 64-72, set./dez. 2001
O resultado deste esforço multiinstitucional deverá ser a padronização do mapeamento de informações (metadados), com enlaces dinâmicos entre os respectivos portais institucionais. Desta forma, será possível acessar teses, dissertações ou artigos a partir do currículo de um autor ou orientador, reforçando o caráter de transparência e acesso público ao acervo nacional de conhecimento.

O Brasil ocupa uma posição pouco privilegiada no cenário científico internacional. Os resultados de pesquisas brasileiras publicados em veículos indexados correspondem a apenas $20 \%$ a $25 \%$ do total ${ }^{21}$. As bases de dados estrangeiras consideradas mais importantes raramente indexam publicações nacionais. Decorre daí que, "se os títulos não são indexados, os autores não são citados, o que fecha um círculo vicioso"22.

Em termos de tendências internacionais, os esforços brasileiros estão em sintonia com estudos recentes sobre a importância da visibilidade da informação digital ${ }^{2}$. Ao difundir a produção científica nacional e viabilizar sua projeção, o BTD, aliado a outras iniciativas brasileiras, tais como outros bancos de teses institucionais, o projeto SciELO (FAPESP/Bireme) e a Biblioteca Digital Brasileira (IBICT), contribui para romper o círculo vicioso que oculta a produção científica nacional da sociedade e, muitas vezes, da própria comunidade científica.

\section{AGRADECIMENTOS}

A constituição do Banco de Teses e Dissertações do PPGEP/UFSC tem origem em uma política de transparência e divulgação de informações implantada pela coordenação do programa em 1995, quando as primeiras teses e dissertações foram digitalizadas. Vários grupos no PPGEP são responsáveis pela realização do BTD. Foram decisivos para sua construção os laboratórios de Mídia e Conhecimento (LMC) e de Inteligência Aplicada (LIA), responsáveis iniciais pela digitalização dos documentos. Atualmente, o crescimento do BTD depende dos alunos e professores do PPGEP/UFSC, que produzem e submetem para publicação as teses e dissertações. A gestão e desenvolvimento do BTD está a cargo do grupo Stela. 


\section{Roberto Carlos dos Santos Pacheco / Vinícius Medina Kern}

\section{REFERÊNCIAS BIBLIGRÁFICAS}

1. MASON, J.; MITCHELL, S.; MOONEY, M.; REASONER, L.; RODRIGUEZ, C. Infomine: Promising directions in virtual library development. First Monday, v.5, n. 6, 2000. Disponível em: <http:// firstmonday.org/issues/issue5_6/mason/index.html >.

2. LAWRENCE, Steve. Online or invisible? Nature, v. 411, n. 6837, p. 521, 2001.

3. BAGGIO, R. A sociedade da informação e a infoexclusão. Ci. Inf., v. 29, n. 2, p. 16-21, 2000.

4. WAhrhaftiG, R.; FerrazA, A. M.; e RAUPP, M. Portas Abertas para a Educação Superior. Universidade Eletrônica do Paraná, 2001.

5. Digital Library of MIT Theses. Disponível em: <http:// theses.mit.edu/>. Acesso em: 20 Nov. 2001.

6. UMI ProQuest Digital Dissertations. Disponível em: <http:// wwwlib.umi.com/dissertations/>. Acesso em: 20 Nov. 2001.

7. Digital Library and Archives. Disponível em: <http:// scholar.lib.vt.edu/theses/>. Acesso em: 20 Nov. 2001.

8. Teses Brasileiras. Disponível em: $<$ http://www.ibict.br/>. Acesso em: 20 Nov. 2001.

9. Banco de Teses e Dissertações da Engenharia Química Brasileira. Disponível em: < http://www2.enq.ufsc.br/banco.html>. Acesso em: 20 Nov. 2001.

10. UNIVERSIDADE FEDERAL DE SANTA CATARINA. Programa de Pós-Graduação em Engenharia de Produção. Banco de Teses e Dissertações do PPGEP. Disponível em: <http://teses.eps.ufsc.br/>. Acesso em: 13 Set. 2001.
11. CUNHA, M. B. Construindo o futuro: a biblioteca universitária brasileira em 2010. Ci. Inf., v. 29, n. 1, p. 71-89, 2000.

12. CUNHA, M. B. Desafios na construção de uma biblioteca digital. Ci. Inf., v. 28, n. 3, p. 257-268, 1999.

13. VERGUEIRO, W. Recensão: Future libraries: dreams, madness \& reality. Ci. Inf., v. 26, n. 2, 1997.

14. CRAWFORD, W.; GORMAN, M. Future libraries: dreams, madness \& reality. Chicago and London: American Library Association, 1995.

15. AREllanO, M. A. M. Serviços de referência virtual. Ci. Inf., v. 30, n. 2, p. 7-15, 2001.

16. SENA, N. K. Open archives: caminho alternativo para a comunicação científica. Ci. Inf., v. 29, n. 3, p. 71-78, 2000.

17. CAPLAN, P. Oh what a tangled web we weave: Opportunities and challenges for standards development in the digital library arena. First Monday, v. 5, n. 6, 2000. Disponível em: <http://firstmonday.org/ issues/issue5_6/caplan/index.html>.

18. PACHECO, R. C. S. e KERN, V.M. Uma ontologia comum para a integração de bases de informações e conhecimento sobre ciência e tecnologia. Ci. Inf., aceito para publicação. Nesta edição, 2001.

19. Dublin Core Metadata Initiative. Disponível em: <http:// www.dublincore.org/>. Acesso em: 20 Nov. 2001.

20. Biblioteca Digital Brasileira. Disponível em: <http://www.ibict.br/ bdb/inicio.htm >. Acesso em: 20 Nov. 2001.

21. MENEGHINI, R. Avaliação da produção científica e o Projeto SciELO. Ci. Inf., v. 27, n. 2, p. 219-220, 1998.

22. TARGINO, M. G.; GARCIA, J. C. R. Ciência brasileira na base de dados do Institute for Scientific Information. Ci. Inf., v. 29, n. 1, p. 103-117, 2000 